\title{
Synthesis, structure, and radioprotective activity of the palladium (II) complex with mexidol
}

\author{
KH. I. GASANOV, S. I. NURULLAYEVA, Z. H. BABAYEV, SH. H. GASIMOV \\ Scientific-Research Center of Azerbaijan Medical University, \\ Baku, AZERBAIJAN \\ Istanbul Medipol University, \\ Istanbul, TURKEY
}

Abstract: New complex compounds of palladium (II) with biologically active ligand 2 - ethyl - 6 methyl - 3 hydroxy-pyridine - mexidol in acidic medium $(\mathrm{pH}=5,3)$ of the following composition have been synthesized $\left(\mathrm{C}_{8} \mathrm{H}_{12} \stackrel{\oplus}{\mathrm{ON}}\right)_{2}\left[\mathrm{PdCl}_{4}\right]$. In this case, the ligand is protonated and as a single-charged cation occupies an external coordination sphere. The structure of the complex is proved by X-ray structure analysis. It is shown that the structure is constructed of an isolated complex anion $-\left[\mathrm{PdCl}_{4}\right]^{2-}$ and cation $\mathrm{C}_{8} \mathrm{H}_{12} \stackrel{\oplus}{\mathrm{ON}}$.

The square planar coordination of the palladium atom is formed from three chlorine atoms and the formed tetraacidoanion ligand forms a hydrogen bond. The average length of $\mathrm{Pd}-\mathrm{Cl}$ bond is $2,3030 \mathrm{~A}$, there are no deviations from 900 valence angles of $\mathrm{Cl}-\mathrm{Pd}-\mathrm{Cl}$. The palladium atom is not shifted from the plane coordination polyhedron (square) and therefore trance angles of Cl-Pd-Cl are 1800. Two different lengths $-2,289 \stackrel{0}{A}$ and 2,713 $\stackrel{0}{A}$ of hydrogen bonds are related to the geometric location of the ligand functional group.

The obtained 2 - ethyl - 6 - methyl - 3 -hydroxypyridinetrachloro - palladium - mexidazole was tested for radioprotective properties. Toxicity of the preparation is LD50 - $240 \mathrm{mg} / \mathrm{kg}$ of animal weight. Toxicological studies of mexidazole in mice, rats and dogs did not reveal cardiotoxic, immunotoxic, embryonic, nephrotoxic, hematoxic and other types of side effects. Mexidazole is removed from the body with urine 5-8 hours after intravenous injection.

The carried out biological test showed that the compound, along with radioprotective properties, has some antitumor activity.

Keywords: palladium(II), mexidol, tetraacidoanion, hydrogen bond,

coordination, ligand, dentation, X-ray structure analysis.

Received: May 3, 2021. Revised: September 1, 2021. Accepted: September 12, 2021. Published: September $24,2021$.

\section{Introduction}

TN recent years, convincing data have been obtained indicating that a violation of the systems of regulation of free radical processes in the body can lead to the development of various pathological conditions (radiation injury, malignant growth, hypoxia, etc.).

In a living organism, free radicals are formed as a result of natural oxygen metabolism, as well as in the processes of redox transformations of various endogenous substrates, drugs, xenobiotics. Primary radicals, specially produced by the body, perform the most important functions, and secondary radicals that have a cytotoxic effect, as a rule, cause great harm to the body $[1,2]$.

Due to the high reactivity of many free radicals, their action in the body is controlled by endogenous and exogenous antioxidants, as well as complex compounds obtained on their basis with various metals [3-5].

The advances in the chemistry of coordination compounds open up broad prospects for the search for new, more advanced methods of diagnostics and treatment of various diseases with the study of such compounds.

Complex compounds of some metals, including platinum (II) and palladium (II) with many bioactive ligands, as well as heterocyclic amines, have different biological properties [6,7]. In this case, an important role is played by the structure and functional groups that make up the biologically active ligand itself.

In this work, 2 - ethyl - 6 methyl - 3 - hydroxy pyridine mexidol was taken as a complexing biologically active ligand

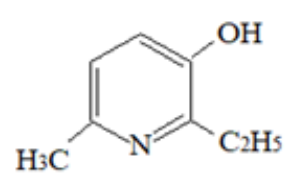

C8H11ON - L C8H12ON - HL

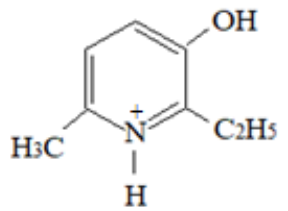

Mexidol, an inhibitor of free radical processes, is a membrane protector that also possesses antihypoxic and antioxidant properties [8-10]. 
There is evidence in the literature that complexes of such ligands have synergistic properties $[11,12]$.

In this regard, the search for new biologically active substances among palladium salts with 2 - ethyl - 6 methyl - 3 hydroxy pyridine is of urgent importance.

There is no information in the literature on complex compounds of Mexidol with metals. For the first time, we synthesized a complex compound of palladium with mexidol in the composition of (HL) 2 [PdCl4] in a wide range of $\mathrm{pH}$ medium and various ratios of reactants (M: L).

\section{Iiexperimental Part}

As a ligand, the used Mexidol was subjected to additional purification from excipients. IR spectra were recorded on Thetmoscientific, Nicoletis 10, and Bruker IFS - 113V spectrometers in vaseline or in a suspension of fluorinated oils, as well as in the form of $\mathrm{KBr}$ tablets. The thermal behavior of the complex was studied on a NETZSCH STA 449 F3 Jupiter derivatograph at a heating rate of $10 \mathrm{deg} / \mathrm{min}$. up to $8000 \mathrm{C}$. The electrical conductivity of the complex was measured on a KEL-1M2 conductometer in aqueous solutions at 250C.

X-ray diffraction analysis was carried out on a Bruker X8 APEX four-circle automatic diffractometer equipped with a two-axis SSD detector at 273 (2) K using molybdenum radiation and a graphite monochromator according to the standard technique.

$$
\begin{aligned}
& \text { Synthesis of the complex. } \\
& \left(\mathrm{C}_{8} \mathrm{H}_{12} \stackrel{\oplus}{\mathrm{ON}}\right)_{2}\left[\mathrm{PdCl}_{4}\right] \quad(\mathrm{HL})_{2}\left[\mathrm{PdCl}_{4}\right] .
\end{aligned}
$$

$\mathrm{PdCl} 2$ with a mass of $0.33 \mathrm{~g}(1.86 \mathrm{mmol})$ with stirring and heating to $60^{\circ} \mathrm{C}$ is dissolved in a mixture of $20 \mathrm{ml}$ of water and $5 \mathrm{ml}$ of concentrated hydrochloric acid. Then the clear red solution is filtered from the partially reduced palladium metal. At the same temperature, $0.51 \mathrm{~g}(3.71 \mathrm{mmol})$ of mexidol dissolved in $15 \mathrm{ml}$ of water is added to the filtered solution and stirred.

The resulting reaction mixture was stirred in a water bath with a temperature of $500 \mathrm{C}$ and the $\mathrm{pH}$ of the solution was adjusted to 5.3. The reaction mixture is evaporated in a water bath at the same temperature to a small volume and cooled in an ice $(+20 \mathrm{C})$ bath; within 40 minutes, light brown needle crystals are precipitated from the solution. The crystals are filtered off, washed with cold ethanol and then with ether. The substance is dried first in air, then in vacuum to constant weight. Yield: $0.81 \mathrm{~g}(83 \%)$.

\section{Results and Its Discussion}

As a result of the interaction of mexidol with a palladium (II) salt in an acidic medium at a metal-ligand ratio of 1:2, a new complex of composition - was synthesized$\left(\mathrm{C}_{8} \mathrm{H}_{12} \stackrel{\oplus}{\mathrm{ON}}\right)_{2}\left[\mathrm{PdCl}_{4}\right]$. The results of elemental analysis are shown in Table 1.
Table 1.

\begin{tabular}{|c|c|c|c|c|c|c|c|c|c|c|}
\hline \multirow[b]{2}{*}{ Complex } & \multicolumn{2}{|l|}{$\mathrm{Pd}$} & \multicolumn{2}{|l|}{$\mathrm{N}$} & \multicolumn{2}{|l|}{$\mathrm{Cl}$} & \multicolumn{2}{|l|}{ C } & \multicolumn{2}{|l|}{$\mathrm{H}$} \\
\hline & Rec. & Calc. & Rec. & Calc. & Rec. & Calc. & Rec. & Calc. & Rec. & Calc. \\
\hline $\begin{array}{l}(\mathrm{HL})_{2} \\
{\left[\mathrm{PdCl}_{4}\right]}\end{array}$ & 20.41 & 20.29 & 5.52 & 5.33 & 27.21 & 27.04 & 36.78 & 36.64 & 4.70 & 4.57 \\
\hline
\end{tabular}

Elemental analysis results of the complex -

For accurate identification of the obtained IR spectroscopic data, the IR spectra of the starting palladium salts, the ligand and the synthesized complex were recorded, and then a comparative corresponding assignment of the absorption band in the IR spectra was made. Comparison of the results of the IR spectra of the free ligand and the synthesized complex $(\mathrm{HL})_{2}\left[\mathrm{PdCl}_{4}\right]$ allows you to unambiguously determine the structure and method of the ligand system in them.

In the IR spectrum of the free ligand molecule, an asymmetric absorption band of the stretching vibration at 1236 $\mathrm{cm}-1$ is observed, which belongs to the $\mathrm{C}-\mathrm{O}$ group. Upon complexation due to hydrogen bonds, this band decreases to $1615 \mathrm{~cm}-1$, which is accompanied by a decrease in the intensity of the band. In the complex, the existence of hydrogen bonds has also been proven by means of RS analysis. Absorption in the range of 1235 and $1290 \mathrm{~cm}-1$ refers to bending vibrations of the free $\mathrm{OH}$ - group $[8,13]$. These facts indicate that the alcoholic hydroxyl group of the ligand does not participate in coordination with palladium.

In the IR spectrum of the uncoordinated ligand, the existing broad absorption band at $3440-3400 \mathrm{~cm}-1$ is attributed to the $\mathrm{C}-\mathrm{N}$ bond of the aromatic ring. Upon complexation in an acidic medium, the pyridine nitrogen atom of the ligand is protonated and occupies the outer sphere as a singly charged ion. This is evidenced by the absorption bands at $3250 \mathrm{~cm}-1$ $[13,14]$.

For the planar [PdCl4]2- anion with the D4h symmetry, the selection rules require the presence of three bands in the IR spectrum: the stretching vibration of $\mathrm{Pd}-\mathrm{Cl}$, of the $\mathrm{Eu}$ symmetry class, and two bending vibrations of the Eu and $\mathrm{A} 2 \mathrm{u}$ classes $\left(\delta_{\mathrm{PdCl}_{2}}^{a s}\right.$ and $\gamma_{\mathrm{ClPdCl}}$, respectively).

The IR spectrum of the $(\mathrm{HL})_{2}\left[\mathrm{PdCl}_{4}\right]$ complex exhibits bands with frequencies of 338,180 , and $172 \mathrm{~cm}-1$, corresponding to $v_{\mathrm{Pd}-\mathrm{Cl}}^{a s}, v_{\mathrm{PdCl}_{2}}^{a s}$ vibrations, and $v_{C l P d C l}$ of the [PdCl4]2- planar anion, which is in good agreement with the literature data [15].

Crystallographic data $\mathrm{a}=7,5927$ (2), в $=17,3196$ (5), $\mathrm{C}=$ 8,5412 (3) $A, \alpha=900, \beta=108,7580$ (10)0, $\gamma=900$, sp.gr. ... 
0

P21/n, V = 1063,53 (6) $A, \mathrm{Z}=4$, dcalc. $=1.638 \mathrm{~g} / \mathrm{cm} 3$. The crystal structure was solved by the standard direct method. It was found that the synthesized phase has a composition $\left(\mathrm{C}_{8} \mathrm{H}_{12} \stackrel{\oplus}{\mathrm{ON}}\right)_{2}\left[\mathrm{PdCl}_{4}\right]$.

The final refinement was carried out in the full-matrix approximation using 2355 independent reflections $\mathrm{CI} \geq 2 \sigma$. Final R-value $=0.0671$. All calculations were performed using the PC-SHELX software package. The atomic coordinates are given in Table 2, and the main bond lengths and bond angles are shown in Table 3 .

X-ray diffraction study of crystals, carried out on a DRON$3 \mathrm{M}$ diffractometer, showed that the synthesized complex is single-phase.

Table 2

Atomic coordinates

\begin{tabular}{|l|l|l|l|l|}
\hline atom & $\mathrm{x}$ & $\mathrm{y}$ & $\mathrm{z}$ & $\mathrm{U}$ eq. \\
\hline $\mathrm{Pd}(1)$ & 5000 & 5000 & 5000 & $40(1)$ \\
$\mathrm{Cl}(1)$ & $7558(3)$ & $4742(1)$ & $4213(3)$ & $61(1)$ \\
$\mathrm{Cl}(2)$ & $4347(3)$ & $6083(1)$ & $3330(3)$ & $54(1)$ \\
$\mathrm{N}(1)$ & $3994(8)$ & $8575(3)$ & $8660(8)$ & $49(1)$ \\
$\mathrm{O}(1)$ & $4133(12)$ & $7627(4)$ & $5022(7)$ & $82(2)$ \\
$\mathrm{C}(1)$ & $3903(10)$ & $8014(4)$ & $9718(10)$ & $49(2)$ \\
$\mathrm{C}(2)$ & $3875(12)$ & $7276(4)$ & $9160(11)$ & $57(2)$ \\
$\mathrm{C}(3)$ & $3945(12)$ & $7121(4)$ & $7574(11)$ & $62(2)$ \\
$\mathrm{C}(4)$ & $4063(11)$ & $7724(4)$ & $6571(10)$ & $55(2)$ \\
$\mathrm{C}(5)$ & $4104(9)$ & $8474(4)$ & $7114(10)$ & $46(2)$ \\
$\mathrm{C}(6)$ & $4209(12)$ & $9182(4)$ & $6127(11)$ & $56(2)$ \\
$\mathrm{C}(7)$ & $2315(14)$ & $9407(6)$ & $4962(13)$ & $82(3)$ \\
$\mathrm{C}(8)$ & $3841(15)$ & $8264(6)$ & $11356(12)$ & $73(2)$ \\
\hline
\end{tabular}

Table 3 .

Bond lengths d, $A$ and bond angles $\omega$, gr. in complex $\left(\mathrm{C}_{8} \mathrm{H}_{12} \stackrel{\oplus}{\mathrm{ON}}\right)_{2}\left[\mathrm{PdCl}_{4}\right]$

The structure of the complex is built of isolated complex [PdCl4]2- anions and mexidol cation. The structure of the complex is shown in Figure 1. The palladium atom coordinates four chlorine atoms to form a tetraacidoanion. The average length of $\mathrm{Pd}-\mathrm{Cl}$ bonds is $2,3030^{A} A$, and the $\mathrm{Cl}-\mathrm{Pd}-\mathrm{Cl}$ bond angles do not deviate from 900. The palladium atom is not displaced from the plane of the coordination polyhedron (square), and therefore the $\mathrm{Cl}-\mathrm{Pd}-\mathrm{Cl}$ trans angles are 1800 $[16,17]$.

There are also facts about a hydrogen bond between the hydrogen atoms of the outer-sphere hydroxyl group and one of the hydrogen atoms of the pyridine ring with the chlorine atom

\begin{tabular}{|c|c|c|c|c|c|}
\hline Communication & $\mathrm{d}$ & Communication & $\mathrm{d}$ & $\begin{array}{c}\text { Hydrogen } \\
\text { bond }\end{array}$ & $\mathrm{d}$ \\
\hline $\mathrm{Pd}(1)-\mathrm{Cl}(1)$ & $2,2949(19)$ & $\mathrm{O}(1)-\mathrm{C}(4)$ & $1,352(10)$ & $\mathrm{H}(3 \mathrm{~A})-$ & 2,713 \\
$\mathrm{Pd}(1)-\mathrm{Cl}(1)^{1}$ & $2,2949(19)$ & $\mathrm{O}(1)-\mathrm{H}(101)$ & 0,8498 & $\mathrm{Cl}(1)$ & 2,289 \\
$\mathrm{Pd}(1)-\mathrm{Cl}(2)$ & $2,3110(17)$ & $\mathrm{C}(1)-\mathrm{C}(2)$ & $1,362(10)$ & $\mathrm{H}(101)-$ & \\
$\mathrm{Pd}(1)-\mathrm{Cl}(2)^{1}$ & $2,3110(17)$ & $\mathrm{C}(1)-\mathrm{C}(8)$ & $1,479(12)$ & $\mathrm{Cl}(2)$ & \\
$\mathrm{N}(1)-\mathrm{H}(1 \mathrm{~N} 1)$ & 0,8997 & $\mathrm{C}(2)-\mathrm{C}(3)$ & $1,398(12)$ & & \\
$\mathrm{N}(1)-\mathrm{C}(1)$ & $1,344(9)$ & $\mathrm{C}(2)-\mathrm{H}(2 \mathrm{~A})$ & 0,9300 & & \\
$\mathrm{~N}(1)-\mathrm{C}(5)$ & $1,361(9)$ & $\mathrm{C}(3)-\mathrm{C}(4)$ & $1,371(12)$ & & \\
\hline angle & $\omega$ & angle & $\omega$ & angle & $\omega$ \\
\hline $\mathrm{Cl}(1)^{1}-\mathrm{Pd}-\mathrm{Cl}(1)$ & 180,0 & $\mathrm{C}(1)-\mathrm{N}(1)-\mathrm{C}(5)$ & $126,2(6)$ & $\mathrm{N}(1)-\mathrm{C}(5)-\mathrm{C}(6$ & $118,0(7)$ \\
$\mathrm{Cl}(1)^{1}-\mathrm{Pd}-\mathrm{Cl}(2)^{1}$ & $90,64(7)$ & $\mathrm{C}(1)-\mathrm{N}(1)-\mathrm{N}(1 \mathrm{~N} 1)$ & 142,5 & $(1)-\mathrm{C}(4)-\mathrm{C}(3$ & $123,2(7)$ \\
$\mathrm{Cl}(1)-\mathrm{Pd}-\mathrm{Cl}(2)^{1}$ & $89,36(7)$ & $\mathrm{C}(5)-\mathrm{N}(1)-\mathrm{H}(1 \mathrm{~N} 1)$ & 91,1 & $\mathrm{P}(1)-\mathrm{C}(4)-\mathrm{C}(5$ & $116,3(7)$ \\
$\mathrm{Cl}(1)^{1}-\mathrm{Pd}-\mathrm{Cl}(2)$ & $89,36(7)$ & $\mathrm{C}(4)-\mathrm{O}(1)-\mathrm{N}(11)$ & 112,1 & $(3)-\mathrm{C}(4)-\mathrm{C}(5)$ & $120,4(8)$ \\
$\mathrm{Cl}(1)-\mathrm{Pd}-\mathrm{Cl}(2)$ & $90,64(7)$ & $\mathrm{N}(1)-\mathrm{C}(1)-\mathrm{C}(2)$ & $116,2(7)$ & $(4)-\mathrm{C}(5)-\mathrm{C}(6)$ & $125,5(7)$ \\
$\mathrm{Cl}(2)^{1}-\mathrm{Pd}-\mathrm{Cl}(2)$ & 180,0 & $\mathrm{~N}(1)-\mathrm{C}(1)-\mathrm{C}(8)$ & $116,6(7)$ & $(5)-\mathrm{C}(6)-\mathrm{C}(7)$ & $111,5(7)$ \\
& & & & & \\
\hline
\end{tabular}

of the formed tetraacidoanion. Two different lengths $(2,289 A$ and $2,713^{A}$ ) of hydrogen bonds are associated with the geometric arrangement of the functional group of the ligand [18].

The structure of the complex is shown in Figure -1 .

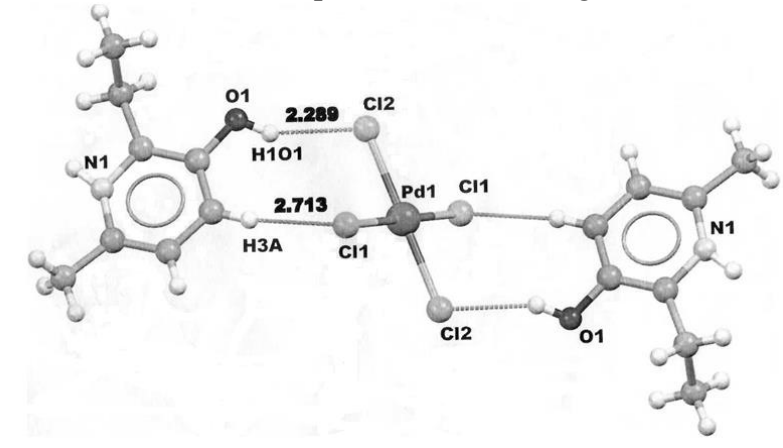

Fig. 1. complex structure $\left(\mathrm{C}_{8} \mathrm{H}_{12} \stackrel{\oplus}{\mathrm{ON}}\right)_{2}\left[\mathrm{PdCl}_{4}\right]$

Thermal decomposition of the complex is more complicated. Figure - 2. At the first stage, weight loss begins at 1400C.

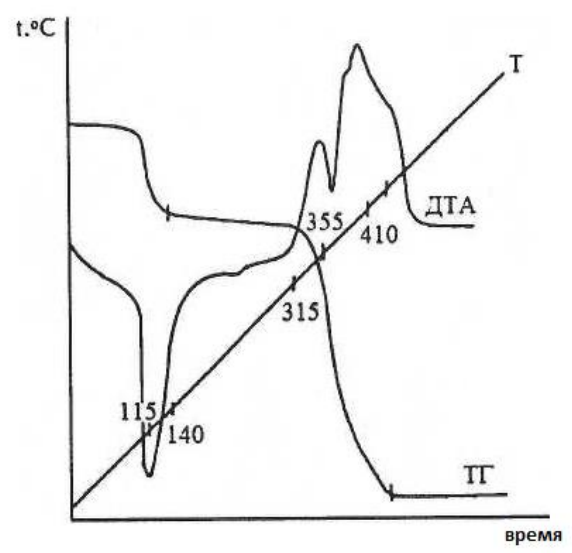


Fig. 2. Derivatogram of the complex $\left(\mathrm{C}_{8} \mathrm{H}_{12} \stackrel{\oplus}{\mathrm{ON}}\right)_{2}\left[\mathrm{PdCl}_{4}\right]$

The cleavage of two ligand molecules is completed at $3150 \mathrm{C}$. The decomposition of the complex and the ligand begins at $3550 \mathrm{C}$ and ends at $4100 \mathrm{C}$ without melting [17]. At this temperature, dehydrohalogenation with migration into the inner sphere of the ligand does not occur.

Thus, the results of IR spectroscopic, XRD, elemental analysis and molar electrical conductivity $(\mu) 1 \cdot 10-3 \mathrm{M}$ aqueous solution of the complex $(224.7 \mathrm{Ohm}-1 \mathrm{~cm} 2 \mathrm{~mol}-1)$ show that the tetraacidoanion - $[\mathrm{PdCl} 4] 2$ - formed. the pyridine nitrogen atom of mexidol in an acidic medium is protonated and as a singly charged cation occupies the outer coordination sphere.

The resulting 2-ethyl-6-methyl-3-hydroxypyridine tetrachloropal-di-oxy-acid-mexidazole was tested for radioprotective properties. The study of radioprotective properties was carried out on white mice. The toxicity of the drug is LD50 - $240 \mathrm{mg} / \mathrm{kg}$ of animal weight.

Extensive toxicological studies of mexidazole in mice, rats and dogs did not reveal cardiotoxic, immunotoxic, embryotoxic, nephrotoxic, hematoxic and other types of side effects. Mexidazole is excreted from the body in the urine 5 to 8 hours after intravenous administration.

It was found that, along with radioprotective properties, mexidazole also possesses some antitumor activity, which is very important in radiation therapy. The combination of pronounced radioprotective properties and antitumor activity characterizes mexidazole from the best side.

Thus, the data obtained indicate the possibility of using mexidazole as a radioprotector, as well as in the treatment of malignant neoplasms. Based on the foregoing, mexidazole can be considered and recommended as a promising compound as a chemotherapeutic agent.

\section{Conclusion}

The results of IR-spectroscopic, X-ray diffraction analysis, elemental analysis and molar electrical conductivity showed that the tetraacidoanion - $[\mathrm{PdCl} 4] 2$ - is formed and the pyridine nitrogen atom of mexidol is protonated in an acidic medium and as a singly charged cation occupies the outer coordination sphere. The resulting 2-ethyl-6-methyl-3-hydroxypyridine tetrachloro-pal-di-acid-mexidazole, along with radioprotective properties, also has some antitumor activity.

\section{Acknowledgment}

This work was supported by the Science Development Foundation under the President of the Republic of Azerbaijan

- Grant EIF-GAT-5-2020-3(37)-12/08/3-M-08

\section{References}

[1] Vlasov A.P., Bunyatov N.D., Bykhanova O.N. Wedge. pharmacokol. and therapy. 2013, No. 1, p. 51 - 54.

[2] Levchenkova O.S., Novikov V.E., Pozhilova E.V. Reviews on Wedge. pharmacokol. and lek.therapy. 2012, T.10, No. 3, p. 3 - 12.

[3] Efimenko I.A., Ivanova N.A., Lokshin B.V. Patent Ru 2291872.C.2. Published 20.012007, Biol. No. 2, 2007.

[4] Efimenko I.A., Ivanova N.A. Eurasian patent No. 010431 dated August 29, 2008. Biol. Inventions No. 4, 2008

[5] El - Sherif A.A. Jornal of Coordination Chemistry. 2011. Vol. 64. № 12. P. 2035 - 2055

[6] S.B. Deepthi, P. Ramech, R.Trivedi. İnorganica Chimica Acta. 2015. Vol. 435.P. 200 - 205.

[7] M.Z. Ghdhayeb, R.A. Haque, S.Budagumoi. Polyhedron. 2017.Vol. 121. P. $222-230$

[8] Novikov V.E., Levchenkova O.S. Experimental Clinical Pharmacology. 2013, T.76, No. 5, p. 37 - 47

[9] Stolyarova VV . Experimental Clinical Pharmacology. 2001, Vol. 64, No. 6, p. 3 - 6.

[10] Sinrov A.V., Ingins V.I., Kinzirsky A.S., Kinzirskaya Yu.A. Problems of Oncology, 2007, V. 53, No. 6, p. 711 714.11. Winterboum C.C., Kettle A.J. Biochem Biophys Res Commun. - 2003, № 305(3), P.729 - 736.

[11] S.Tetteh, D.K.Dodgo, R. Appiah - Opong, I. Tuffour Ttansition Met. Chem. 2014. Vol. 39. P. $667-674$.

[12] 13. I.Mitr, S.Mukherjee New J.chem. 2018. Vol.42. P. $2574-2589$

[13] 14. A.V.Vasiliev, E.V. Grinenko, A.O.Shukin, T.G. Ferumina. St. Petersburg 2007.70 p.

[14] 15. Kas'yanenko N.A., Levykina E.V., Erofeeva O.S., Ivanova N.A., Efimenko I.A. Journal of Structural Chemistry. 2009, Vol. 50, No. 5, p. 1034 - 1044.

[15] 16. S.L.Khranenko, I.A.Baidina, N.V. Kurat'eva, S.A. Gromilov. Journal of Structural Chemistry. 2009.T.51. No. 1.s.173 - 176.

[16] 17. C. Biswas, M. Zhu, L.Lu., Polyhedron. 2013. Vol.56. P.211 - 220

[17] 18. Brandi P., Sani M.P., Muller B., Bardaji E.G., Willerman M., Lipperi B. Inorq. Chem. - 2009.-48. № 12. P.5208 - 5213.

\section{Creative Commons Attribution License 4.0 (Attribution 4.0 International, CC BY 4.0)}

This article is published under the terms of the Creative Commons Attribution License 4.0 https://creativecommons.org/licenses/by/4.0/deed.en_US 